\title{
Interesting news from the annual meeting of the American Society of Hematology 2020
}

\author{
Eberhard Gunsilius
}

The 62nd annual meeting of the American Society of Hematology, the most influential meeting in hematology, was held (formally in San Diego, CA, USA) as an all-virtual meeting from December 5-8, 2020. Apart from outstanding contributions "from the bench" with the potential to find a way into diagnosis and treatment, a plethora of clinical trials, many in early clinical phase investigating novel compounds, were presented. In this issue of $M E M O$, selected presentations that are relevant for our daily practice or are likely to become relevant in the near future are highlighted by esteemed colleagues, to whom I express my thanks for the preparation of their manuscripts.

Dr. Prochazka and Dr. Neumeister present relevant findings on chronic lymphocytic leukemia, including some news about coronavirus disease (COVID) vaccination in this vulnerable patient group [1]. Dr. Böhm and Dr. Keil present the highlights on allogeneic and autologous transplantation, including data on posttransplant immunosuppression with cyclophosphamide after mismatch transplantation and ruxolitinib for the treatment of graft-versus-host disease, the significance of autologous stem cell transplantation (SCT) in acute lymphoblastic leukemia and multiple myeloma and the possibility of allogeneic stem cell transplantation in elderly patients with high-risk myelodysplasia [2]. I myself summarize the main topics on multiple myeloma, illuminating the dramatic improvement in patients outcome with combinations of novel compounds and the persistent benefit of autologous stem cell transplantation in transplant eligible patients [3]. T-cell based strate- gies, such as CAR-T cells and monoclonal antibodies that recruit $\mathrm{T}$-cells to the malignant cells (bispecific T-cell enhancers [BITE]) are currently tested in clinical trials and show impressive clinical results even in heavily pretreated patients and will enrich our therapeutic armamentarium in the near future, although with considerable financial toxicity for the health care systems.

What we have missed are the personal contacts and discussions with friends and colleagues. We all hope that in the foreseeable future, "real" meetings can be held again so that we can maintain or build up personal and scientific relationships.

Conflict of interest E. Gunsilius declares that he has no competing interests.

\section{References}

1. Prochazka KT, Neumeister P. Chronic lymphocytic leukaemia-what is new and notable in 2021, with a special focus on COVID-19. memo. 2021. https://doi.org/ 10.1007/s12254-021-00735-z.

2. Böhm A, Keil F. New trends in autologous and allogeneic stem cell transplantation - an update from the annual ASH meeting 2020. memo. 2021. https://doi.org/10.1007/ s12254-021-00725-1.

3. Gunsilius, E. Multiple myeloma: my highlights at ASH 2020. memo. 2021. https://doi.org/10.1007/s12254-021-00746w.

Publisher's Note Springer Nature remains neutral with regard to jurisdictional claims in published maps and institutional affiliations.

\footnotetext{
Univ.-Doz. Dr. E. Gunsilius ( $\bowtie)$

Department of Hematology and Oncology, Medical

University Innsbruck, Anichstraße 35, 6020 Innsbruck, Austria

eberhard.gunsilius@tirol-kliniken.at
} 